\title{
Modelling detailed information flows in building design with the parameter- based design structure matrix
}

Şule Tassll Pektass and Mustafa Pultar, Faculty of Art, Design and Architecture, Bilkent University, 06800 Bilkent, Ankara, Turkey

The Architecture/Engineering/Construction (AEC) industry is one of the multidisciplinary domains in which collaboration among related parties is of utmost importance. Despite the intense flow of information between design professionals, there is a lack of research to better understand and manipulate these flows. Most of the current process modelling tools in the AEC industry do not enable analyses of iterative information cycles.

Moreover, these tools represent the process at high levels, thus, they are inadequate for multi-parameter problems like building design. With a view to alleviate these problems, this paper introduces the use of parameter-based design structure matrix as a process modelling and system analysis tool for building design. The method reveals insights into the process structure, optimum sequence of parameter decisions, iterative cycles and concurrency in the process. The application of the method is demonstrated through a case study on suspended ceiling design in a reallife project.

(C) 2005 Elsevier Ltd. All rights reserved.

Keywords: design management, design processes, modelling, planning, information processing

Corresponding author: S. T. Pektaş tasli@bilkent.edu.tr

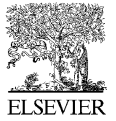

7 he increasing complexity of buildings and a very competitive marketplace have been forcing design professionals to improve their processes in terms of time and quality. However, systematic design planning is not performed in many building projects (Formoso et al., 1998; Rounce, 1998). Even when planning is done, it is performed in an intuitive manner based on discipline specific programs, despite the fact that effective design collaboration necessitates planning the flow of interdisciplinary information. Relatively little research has been done on the management of the design process compared to production management in construction.

The lack of design planning in Architecture/Engineering/Construction (AEC) projects is largely due to the fragmentation of the AEC industry. The larger organizations in other industries, such as the

www.elsevier.com/locate/destud

0142-694X \$ - see front matter Design Studies 27 (2006) 99-122

doi:10.1016/j.destud.2005.07.004 
automotive, the aerospace, and the electronics industries, have higher profits that enable them to invest larger sums of money in process reengineering and they have a few key organizations that can drive a technology to suit their requirements. On the other hand, design teams consist of smaller groups of design professionals in the construction industry. Moreover, teams often consist of different members per design task and costs of design planning are not often included in architects' fee. All the factors mentioned above hinder widespread application of design planning in the industry. Successful management of design, however, is critical to quality, cost effectiveness and timeliness of projects. In a survey of AEC companies in the U.S. (Arditi and Günaydın, 1998), collaboration among parties ranked first among the many factors that affect quality in design phase. Cornick (1991) has estimated the cost of rectifying building design failures to be between $12 \%$ and $15 \%$ of total European construction expenditure. From time point of view, as well, design-caused wastes form the largest category (Rounce, 1998).

This paper addresses the problem of design management from an information flow perspective. The collaborative building design process is viewed as an iterative flow of interdependent decisions of different design professionals. A review of the existing process models used in the construction industry revealed that existing models do not support such a level of granularity in modelling. Thus, in this paper, parameter-based design structure matrix (DSM) is proposed as a low-level process modelling tool which is capable of alleviating the deficiencies of the existing tools. Parameter-based DSM is a structured analysis technique which aims to capture dependencies between decisions on design parameters. It also provides means to sequence those decisions according to the dependency structure. The method has been applied previously in the automotive industry (Black et al., 1990; Cesiel, 1993; Dong, 1999), robot arm design (Rask and Sunnersjö cited in Browning, 2001), aeroengine design (Mascoli, 1999) and software development (Rogers and Salas, 1999); however, to the best of our knowledge this study is the first to utilize it in building design.

\section{Design process models}

Process models of design aim to capture complexities of design processes and they can facilitate for improving them. This type of modelling is based on the premise that although designs may be unique in different projects, the process of designing has an underlying structure which does not vary much across the projects. 
The process modelling efforts in the AEC industry can be considered under two general headings: generic descriptive frameworks and formal activity models. Descriptive methodological and philosophical frameworks of the design process originate from the Design Methods movement of the 1960s and include Hubka (1982), Pahl and Beitz (1984), Cross (1989) and Pugh (1986) to name a few. The RIBA Plan of Work (Phillips, 2001) and the Generic Design and Construction Process Protocol (GDCPP) developed at the University of Salford (Wu et al., 1998) are other high-level maps of building design process. A common characteristic of generic models is that they represent design process in terms of the stages within it. Thus, they provide a good overview of the design process, but they are often too abstract to be utilized in managing detailed design processes due to their high-level content and descriptive nature. They are more effective as guidelines rather than analysis tools.

Formal models that focus on representing processes at activity level include network models, information modelling methods and activitybased DSM. Network models can overcome some of the drawbacks of generic models by exploiting activity relationships. These include the Critical Path Method (CPM) and its derivatives (Pultar, 1990), Petri nets (Wakefield and Damrianant, 1999), data flow diagrams (Baldwin et al., 1999) and the Integrated DEFinition Language 0 (IDEF0) (Sanvido and Norton, 1994; Karhu, 2000). Information modelling methods like Entity Relationship (ER) diagrams (Hong and Hong, 2001) and Unified Modelling Language (UML) (Rezgui et al., 2002) were originally developed for designing software intensive systems but they are also used for process modelling purposes.

Formal activity models have been used for process modelling in the AEC industry with varying degrees of success; however, a close examination of them reveals the following deficiencies:

1. Building design is characterized by iteration (rework). However, many process models cannot represent iterative processes; even the models that are capable of identifying iterations do not provide means for managing them.

Design iteration implies rework or refinement, returning to previously made decisions to account for changes. It is typically necessary for two reasons; an unexpected failure of a design to meet established criteria, and an expected response to information which was generated after the previous iteration was completed. The former is called unexpected iteration and the latter is called expected iteration (Smith and Eppinger, 
1999). Failure to converge to design specifications can require unexpected iteration. Unexpected iterations also arise from new information arriving late in the process (caused by out of sequence activities, mistakes, etc.). Expected iteration usually results from downstream activities (particularly verification and validation activities) revealing aspects of upstream activities that must be reworked. Typically, some of the design decisions are made even though the information needed to complete them fully is not known. As this input information becomes available, the tasks are repeated and the product comes closer to meeting the design specification. Rework can also be generated by changes in the information provided to and received from concurrent or interdependent (coupled) activities. Also, when downstream or coupled activities create rework for upstream activities, the resulting changes may cause second order rework for interim activities (those between the upstream and downstream activities directly involved in the iteration).

Although iteration occurs in all design projects, systematic means for iteration management are not established in the construction industry. Conventional project management techniques such as CPM and PERT lack the ability to model feedback and iteration in the projects, since they allow only one-way progression in activity sequences. Browning (1998) explains that the first step towards reducing design cycle time lies in minimizing unintentional iterations. The DSM method facilitates for this purpose by providing optimum sequences of design decisions according to their dependency structure. The next step towards accelerating the design cycle involves two basic options for managing intentional iterations:

1. Faster iterations.

2. Fewer iterations.

Faster iterations can be achieved by improved coordination, e.g. CAD systems that accelerate individual activities, integration of engineering analysis tools used for different purposes, and removal of extraneous activities from the process. Concurrent work is often seen as a way to reduce cycle time but, if concurrent activities are chosen arbitrarily without considering their dependencies, this can lead to abundant iteration and increased cycle time. Krishnan (1993) showed that there is an optimum amount of activity overlapping beyond which additional is not useful and that DSM analysis can help to determine that optimum point. Fewer iterations result from improving the structure of design processes, e.g. activity decoupling and improved activity sequencing which can also be achieved with DSM. 
2. The complexity of design processes entails detailed analyses to gain insight into process structures. However, current process models used in the industry have a top-down approach including very little information about interrelationships at lower levels.

Most of the design process models used in the industry take a top-down approach and they rarely reach the lowest level of design activity where individual design parameters are determined on the basis of other parameters. Determining these parameters corresponds to the lowest-level design activities, and a bottom-up analysis of low-level activities can provide valuable insights into the process structure.

One of the reasons why many process models fail to represent the detailed process is because of the intricacy it adds. Graphical models become so tangled as the process is represented at lower levels that the descriptiveness of the tools diminishes. The DSM method works well in such situations, since it is a compact, visual and analytically advantageous format for complex systems.

Developments in the computer technology have supported the building and managing detailed models. When standardization efforts were begun in building product modelling in 1980s, the focus was on general system models. As the field matured, the models were refined and detailed (Tolman, 1999). Process modelling is relatively new in the AEC industry compared to product modelling. Thus, it can be expected that building design process modelling would follow the same path toward comprehensive and low-level models. The DSM method is likely to benefit from advantages of computerized applications, since matrices can be manipulated easily by computers.

3. Most of the process modelling methods used in building design have been borrowed from the manufacturing industry and they model design process as 'document production' rather than a dynamic decision making process.

In conventional practice, design process is planned around the due dates of documents (e.g. drawings and design reviews) via a master programme which is shared by the design team. Even the structured techniques adapted to building design, for example IDEF0, take only the document producing activities into consideration for modelling. This approach is sensible in practical terms. However, all the information necessary for coordinating design teams is not manifested in documents. Instead, an important amount of information flows by informal 
Table $1 \mathrm{~A}$ three-level scheme for building design process modelling

\begin{tabular}{lll}
\hline Modelling level & Tools & Application areas \\
\hline Process & $\begin{array}{l}\text { Descriptive generic } \\
\text { frameworks }\end{array}$ & Process overview, generic guideline \\
Activity & $\begin{array}{l}\text { Activity models } \\
\text { Parameter-based DSM }\end{array}$ & $\begin{array}{l}\text { Activity sequencing } \\
\text { Low-level activity sequencing, system } \\
\text { architecture analysis }\end{array}$ \\
\hline
\end{tabular}

communication. When the process model includes merely formal activities, this valuable information is lost. An advantage of the DSM method compared to the other methods is its ability to model informal communication. In this way, the method can provide better understanding of organizational problems (Malmström et al., 1999).

In order to alleviate the deficiencies of current design planning processes, we propose the parameter-based DSM method as a low-level analysis tool that can complement existing process- and activity-level models. Table 1 shows a three-level scheme for process modelling in building design; parameter-based DSM is presented as the lowest-level process modelling method.

\section{A brief review on DSM}

The design structure matrix (also known as dependency structure matrix) method has its roots in the 1960s, when several efforts were devoted to solving systems of equations. Donald Steward (1981) first coined the term 'design structure matrix' and applied these concepts to design. The method gained more credibility as a result of several researches at the Massachusetts Institute of Technology in 1990s.

A design structure matrix is a matrix representation of a system or a project. System components are listed in the first row and the first column of the matrix. Off-diagonal cells indicate the interactions (i.e. dependency, information flow) between system elements. There are two main categories of DSM; namely, static and time-based (Figure 1). Static DSMs represent existing system elements simultaneously, such as components of a product architecture or groups in an organization. In time-based DSMs, the ordering of the rows and columns indicates a flow through time; upstream elements of a process precede downstream elements, and terms like 'feedforward' and 'feedback' become meaningful when referring to interfaces.

There are three dependency configurations that characterize a system in time-based DSMs (Figure 2). Between parallel (independent) activities no information exchange is required. These activities can be executed 
Figure 1 DSM taxonomy (adapted from Browning, 2001)

Figure 2 Three configurations that characterize a system in DSM analysis (adapted from MIT DSM, 2005)

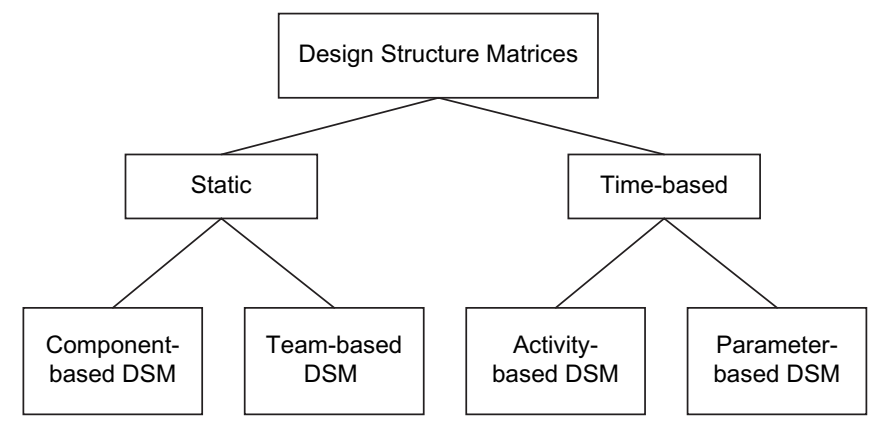

simultaneously. Sequential (dependent) activities require sequential information transfer and they are typically performed in series. Coupled (interdependent) activities are mutually dependent on information and they often require multiple iterations to complete. The DSM method facilitates for minimizing iterations in the process. Partitioning and tearing are two operations used for this purpose. Partitioning is the process of reordering the DSM rows and columns so that the new arrangement does not contain iterations (i.e. the DSM is transformed into lower triangular form). For complex systems, it is often impossible to obtain a lower triangular form DSM by partitioning. In this case, the aim is to move the feedback marks as close as possible to the diagonal so that fewer system elements are involved in the iteration cycle (this results in a faster development process). Tearing is the process of choosing the set of feedback marks that if removed from the matrix will render the matrix lower triangular. The marks that are removed from the matrix are called 'tears.' Identifying the tears that result in a lower triangular matrix means that the set of assumptions that need to be made in order to start design process iterations.

Activity-based DSM is probably the most exploited DSM type among the others. It has been previously applied in automotive (Krishnan,

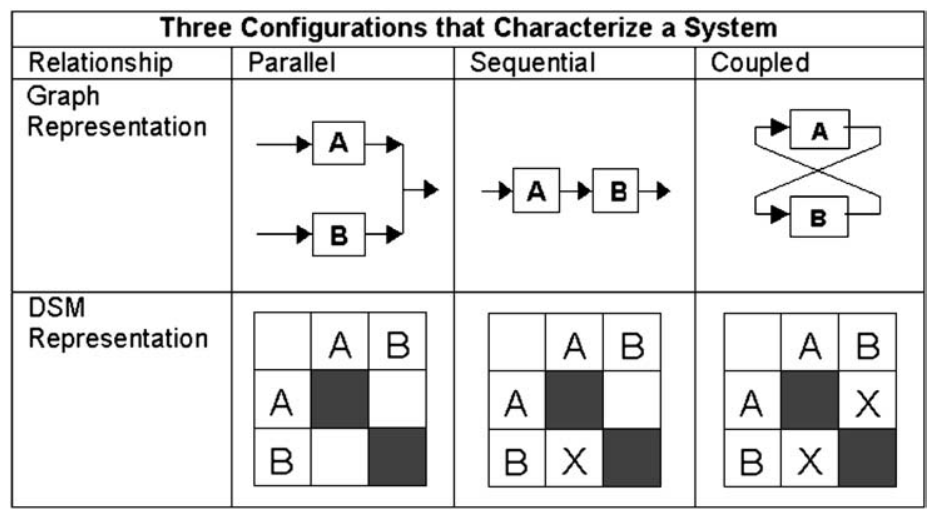


1993), aerospace (Rogers and Salas, 1999; English et al., 2001) and manufacturing industries (Eppinger et al., 1994; Tang et al., 2000). The technique has been used in the construction industry by VTT in Finland (Huovila and Seren, 1998) and Loughborough University (Austin et al., 1999). The research team at Loughborough University has developed a DSM-based design planning technique called Analytical Design Planning Technique (ADePT), the effectiveness of which has been shown in previous research. ADePT has been influential on design process modelling field and it was integrated into more comprehensive planning systems (Choo et al., 2004; Austin et al., 2002).

\section{The parameter-based DSM method}

The proposed parameter-based model of design process is based on an understanding of the design process as a series of decisions on parameter values. Oxford English Dictionary (Hornby et al. (ed.), 1995) defines the word 'parameter' as 'something that decides or limits the way in which something can be done.' This definition implies that parameters should be conceived in a network of dependency relationships. In Computer Aided Design (CAD) literature the term 'parameter' is often used as a synonym to 'attribute' which stands for a quality or a feature. These definitions are fairly broad to be of use in analytical work. This paper, on the other hand, takes a more focused approach and defines a parameter as a physical property whose value determines a characteristic or behaviour of a system component.

Being close both to product and process architectures, parameters are the core concepts of designing; thus, they are increasingly becoming a focus of attention in CAD tools. Earlier geometry-based models have been augmented by parametric models (Rotheroe, 2002; Rundell, 2002). In the process modelling field, their importance is also being increasingly recognized. Rouibah and Caskey (2003) identify an emerging 'parameter-based concurrent engineering' paradigm in engineering design where parameter decisions are considered as the basis of the process. de la Garza and Alcantara (1997) used parameter dependency network to represent design rationale in civil engineering. Clarkson and Hamilton (2000) proposed a parameter-based model of design process called 'signposting' and they demonstrated the application of the model in the design of helicopter rotor blades.

A parameter-based DSM is a square matrix, which defines the dependencies of parameter decisions. The tool is similar to activity-based DSM, but it is used for low-level process sequencing. Thus, the level of analysis constitutes a main difference between activity- and 
parameter-based DSMs. These two types of DSMs also differ in the scope of their representations. While an activity-based DSM includes reviews, tests, and analyses, a parameter-based DSM documents the physical and rational relationships between the parameters that determine design. In other words, a parameter-based DSM describes design processes close to the product architecture (Pektaş, 2003a).

The application of the tool is best described by a simple example. The relationships between seven parameters affecting plenum depth decision for a suspended ceiling design are shown in an initial parameter-based DSM in Figure 3(a). The existence of a dependency is shown by an X. Reading across a row shows input resources; reading down a column shows output sinks. For example, the marks in row $\mathrm{E}$ denote that parameter $\mathrm{E}$ requires information from parameters $\mathrm{C}$ and $\mathrm{D}$. If the parameter decisions were made in the order of A through $\mathrm{G}$, it would be desirable for all information required by each parameter to have been already generated by a predecessor parameter decision. It can be seen in Figure 3(a) that this is not the case for some of the parameters. Parameter B, for example, requires information from parameters A and G. However, information from the parameter $G$ has not been made available. Thus, the decision about the value of parameter $\mathrm{G}$ needs to be made before that for $\mathrm{B}$. If the sequence of parameters was changed so as to have a lower triangular matrix, with all the marks below the diagonal, an optimum sequence for parameter decisions could be realized. This re-ordering is achieved by using some partitioning algorithms; the resulting matrix is shown in Figure 3(b). As can be seen in the figure, however, there is a further problem: a two-way dependency loop or coupling exists between parameters $C$ and E. Complex processes like building design include many such problems and DSM is very useful for identifying them. The following section demonstrates how the DSM method can be applied in real-life design tasks.

\section{A case study on suspended ceiling design process}

Two case studies were undertaken to utilize parameter-based DSM in real-life building design problems. The first case study is based on an

(a)

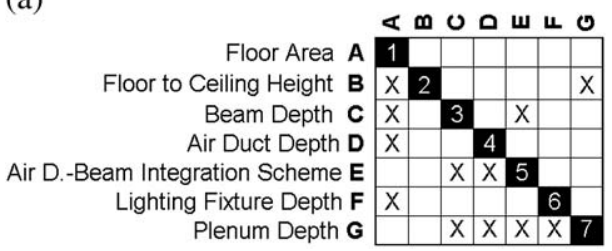

(b)

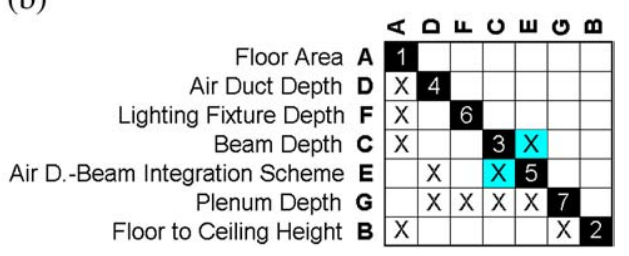

Figure 3 (a) The initial matrix. (b) The partitioned matrix 
analysis of suspended ceiling design process for a public building in Turkey. The DSM analysis for this case aims to capture the information flows in a specific design configuration. The second case study, which analyzes elevator design, however, aims to produce a generic model of elevator design process. Both of these approaches have been validated in previous DSM researches (Browning, 1998). Within the scope of this paper, only the suspended ceiling design case study is discussed. An extensive discussion of both studies is presented elsewhere (Pektaş, 2003b).

Suspended ceiling design is one of the tasks of a whole building design process in which several subsystems interact with each other. This study analysed suspended ceiling design using a system view of suspended ceiling (Figure 4). According to this view, the basic components of a suspended ceiling system are panels, main runners and cross-tees, plenum, hangers, and wall angles. The collection of these members constitutes the suspended ceiling assembly. Assembly-level DSM of suspended ceiling design consists of relations between assembly parameters. Suspended ceiling assembly interacts with four other building systems; namely, Heating, Ventilating and Air-Conditioning (HVAC) distribution system, the structural frame system, the lighting system and the floor construction system. The integration of structural members, lighting fixtures, diffusers, and air ducts in plenum constitutes the major problem in design. The situation is complicated further by the

Figure 4 A system design view of suspended ceiling

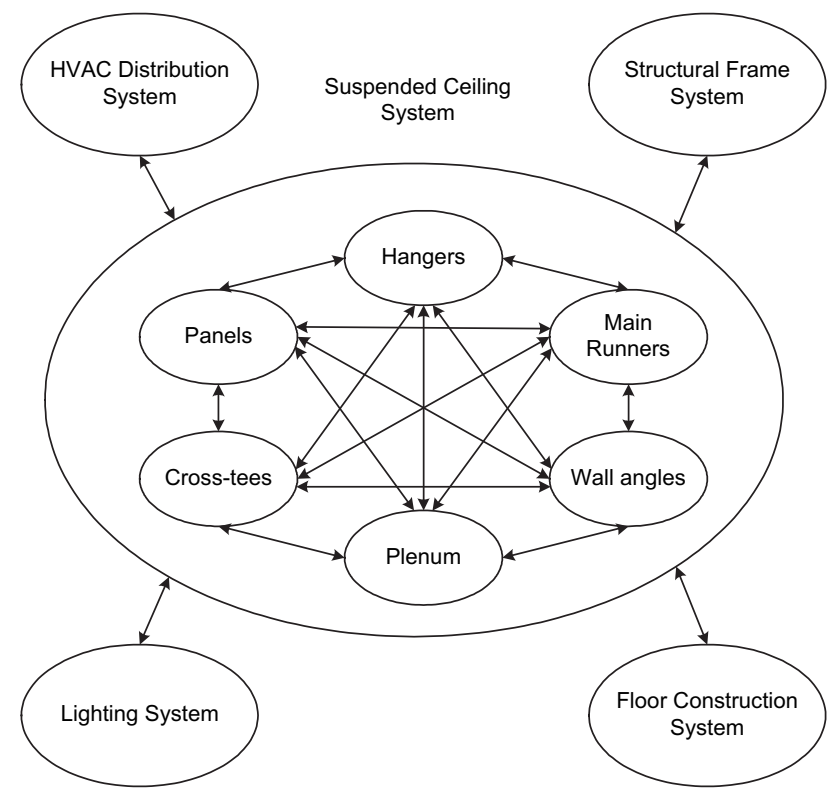

Design Studies Vol 27 No. 1 January 2006 
fact that the elements involved lie in the domains of different building professionals; structural members being designed by structural engineers, diffusers and air ducts by mechanical engineers, and lighting fixtures by electrical engineers. Therefore, the effective (timely, costefficient and quality) design of a suspended ceiling necessitates intensive coordination of these participants. The system-level DSM of suspended ceiling design consists of relations between assembly parameters and parameters belonging to the four other interacting systems.

\subsection{Research setting}

The research was carried out in the architectural design department of TEPE Construction Company, one of the biggest construction companies in Turkey, and in the offices of their engineering collaborators. The engineering collaborators are privately owned firms led by a chief engineer. Design staff employed at these offices includes approximately 4-5 people in each office. Thus, the collaboration between TEPE and its engineering collaborators is an example of a distributed collaboration of small design teams, which constitutes the most widespread model in the Turkish AEC industry. The chief architect of the architectural design department of TEPE, and three engineering collaborators (one structural engineer, one mechanical engineer, and one electrical engineer) provided inputs for this research.

\subsection{Objectives of the analysis}

The objectives of the analyses are listed below.

1. Identify and document important relations specific to suspended ceiling assembly and its interfaces including structural frame system, floor system, HVAC system, and lighting system.

2. Study information flow and coupling in suspended ceiling design.

3. Identify critical parameters that cause large iteration cycles.

4. Identify assumptions made in the process.

5. Show knowledge ownership.

6. Define performance requirements for suspended ceiling design and demonstrate how requirements drive design.

7. Compare assembly-level DSM with system-level DSM in terms of dependency intensity, amount and scope of iterative loops and percentage of information flow contents regarding performance requirements.

\subsection{Collection of the data}

DSM analysis of processes requires collection of the data through inspection of design documents and interviews with designers. This is 
often an iterative and time-consuming process. Deeper understanding of the system usually results in modification of the parameter relationships. However, once an initial model is produced, it constitutes the base for further development.

Data for DSM analysis can be collected by participating in design sessions or by interviews after the completion of design process. Both of these approaches have been validated in DSM literature (Browning, 1998). In our study, the latter approach was taken and the data were collected through iterative cycles of detailed interviews which were recorded by a sound recorder. Besides the interviews, the brief, the drawings, and the manufacturers' information were examined in the study. The initial set of system elements was identified after the initial interviews and they were validated by the experts. The system elements contained not only the physical components in the system, but also performance requirements. The reason for including the performance requirements in the DSM was to see their relationships with design parameters, and to compare assembly- and system-level design from this point of view. All the information flows with the performance requirements satisfied were captured in a database. In Figure 5, 'Content of Information Flow' column shows the reason of information exchange in terms of performance requirements, i.e. shows performance requirements that are satisfied by a specific flow of information between two parameters.

During the data collection process it was observed that even experienced design professionals such as the architect and the engineers interviewed, had not systematically thought about all aspects of the design. The participants responded to the interviews very positively, because these interviews made them think from a systems point of view. In previous DSM examples from product and machinery design field, the researchers had benefited significantly from the documentation of the participating

\begin{tabular}{|l|l|l|}
\hline \multicolumn{1}{|c|}{ From } & \multicolumn{1}{|c|}{ To } & Content of Information Flow \\
\hline Floor Area & Air Duct Width and Length & Thermal Performance \\
\hline Floor to Ceiling Height & Lighting Fixture Quantity & Lighting Performance \\
\hline Lighting Fixture Weight & Main Runner and Cross Tee Face Dimension & Structural Safety \\
\hline Air Diffuser Weight & Main Runner and Cross Tee Face Dimension & Structural Safety \\
\hline Lighting Fixture Layout & Air Diffuser Layout & Aesthetics/Appearance \\
\hline Space Function & HVAC Distribution Layout & Operational/Maintenance Performance \\
\hline Space Function & Services Equipment Maintenance Req. & Privacy \\
\hline Required Depth for HVAC Equipment & Plenum Depth & Spatial Fit \\
\hline Required Depth for Lighting Equipment & Plenum Depth & Spatial Fit \\
\hline Structural Element Connection Details & Plenum Depth & Spatial Fit \\
\hline Beam Depth & Plenum Depth & Spatial Fit \\
\hline
\end{tabular}

Figure 5 Information-providing, -receiving parameters and contents of information flows 
design organizations (Cesiel, 1993; Dong, 1999; Mascoli, 1999). In our study, however, such documentation was very limited, if it existed at all. This probably points to a difficulty in the building design industry in terms of documenting and guiding processes.

\subsection{Production of the matrices}

Using an algorithm (Pektaş, 2003b:p 218) the first draft of the DSMs was produced automatically according to the previously produced database. In the second phase of the data collection process, the draft of the DSMs was shown to the participants and their comments were received. The models were finalized according to the feedbacks from the designers.

\subsection{Analyses and results}

A partitioning algorithm (Pektas, 2003b:p 223) was used to provide an optimum sequence of parameter decisions and to identify couplings in the process. The partitioning process was purely based on the defined interrelationships between the parameters as is common for parameterbased DSM analyses. The resulting matrices are shown in Figures 6 and 7. The assembly-level DSM and the system-level DSM were compared in terms of dependency intensity, total number of elements in loops and percentage of information flow content.

The suspended ceiling system interface DSM contains 165 entries (interaction points, or DSM marks all of which refer to the information flows), while the assembly DSM contains only 97 . The number of system elements are similar in both (approximately 40). Therefore, the suspended ceiling system interface is a more complicated problem than the suspended ceiling assembly design. While the system-level DSM contains large iteration loops, the assembly-level DSM includes only two very small loops. Sixty percent of the elements of the system-level DSM are in one or more loops; but only $11 \%$ for the assembly-level DSM (Table 2). A tearing analysis was performed for the system-level DSM and it was observed that the loops could not be reduced further.

The partitioned DSM of suspended ceiling assembly indicates that parameter decisions at assembly level are made either in a parallel or sequential manner, but at the system level there are couplings. Previous research showed that the time required for humans to solve a coupled parameter design problem rises geometrically as coupling size rises linearly (Hirschi and Frey, 2002). This suggests that although suspended ceiling design is simple, it may take more time than planned due to the iterations at the system level. 


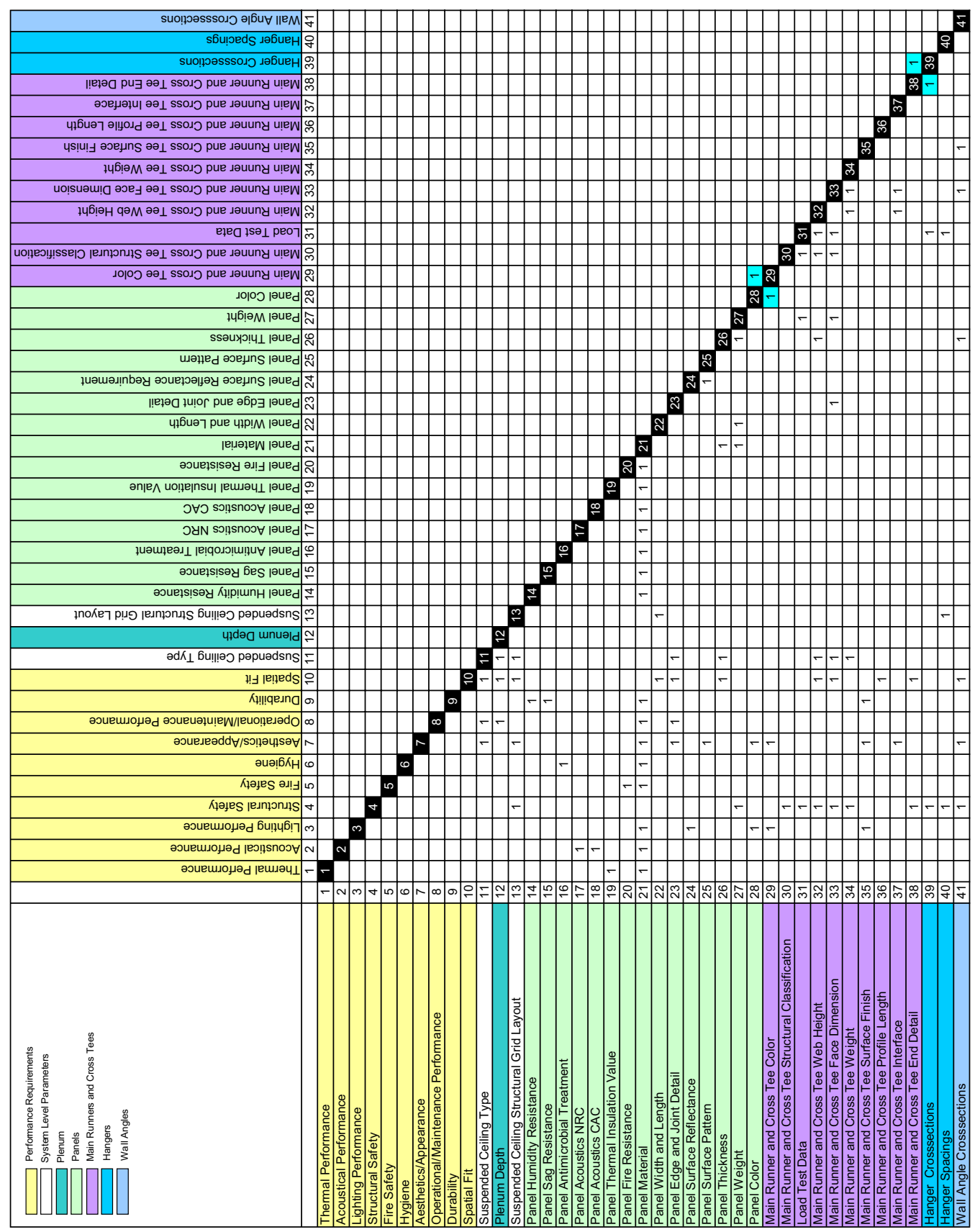

Figure 6 The partitioned assembly-level DSM of the suspended ceiling design process 


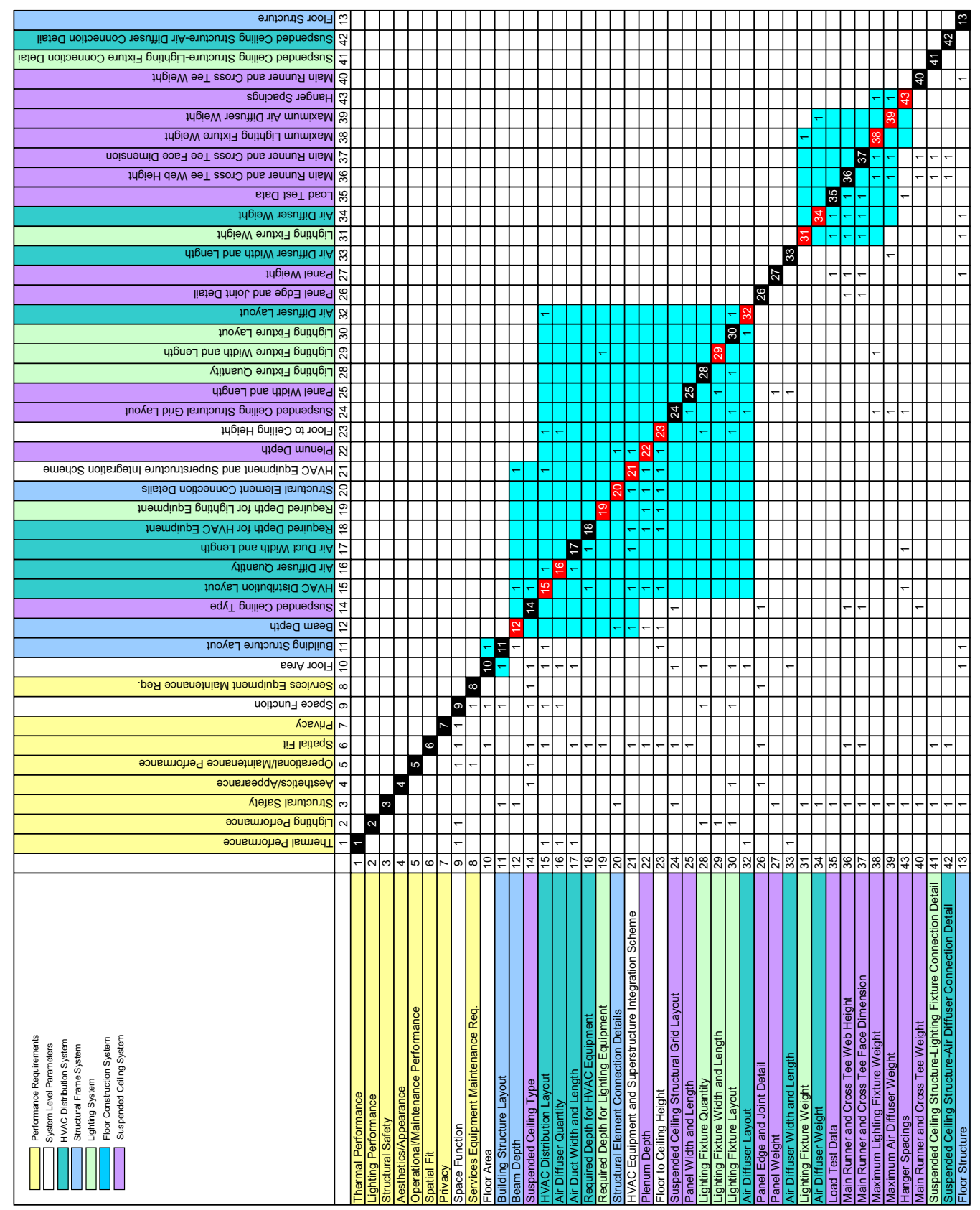

Figure 7 The partitioned system-level DSM of the suspended ceiling design process

Modelling detailed information flows in building design 


\begin{tabular}{lcc}
\hline & Assembly-level DSM & System-level DSM \\
\hline $\begin{array}{l}\text { Total number } \\
\text { of system elements }\end{array}$ & 41 & 43 \\
$\begin{array}{l}\text { Total number } \\
\text { of DSM entries (marks) }\end{array}$ & 97 & 165 \\
$\begin{array}{l}\text { Total number } \\
\text { of parameters in loops }\end{array}$ & 4 & 26 \\
\hline
\end{tabular}

Decisions on some parameters affect a large number of parameters in building design. Consequently, the changes in those 'critical' parameters are more likely to cause larger iteration cycles. Fifteen critical parameters (such as plenum depth, lighting fixture quantity and weight, etc.) were defined for suspended ceiling design at system level; however, there were no critical parameters at the assembly-level design. Critical parameters were identified by manual manipulation and observation of the matrices. Although this technique produced satisfactory results for our study, there is a more systematic approach to identify critical parameters based on coupling strengths (Chen et al., 2003) which can be used in further research. The schedule of the assumptions made in the process was also identified. For example, it is observed that correct assumptions about floor to ceiling height, air diffuser quantity and the integration scheme of HVAC and superstructure at the beginning of the process are likely to prevent costly changes in the HVAC distribution layout.

The percentage contents of information flows were calculated for both assembly and system-level DSMs according to the data illustrated in Figure 5. The results are shown in Figure 8.

\section{Implications on the design process drawn from the case study}

Besides the insights gained into the individual design processes, some common implications can be drawn from the case study.

The first observation about the design processes concerns the types of information flows. There are at least four types of knowledge used in determining the parameter values:

1. There exist a number of formulas, through which existing design values are used to compute a new parameter value. These formulas are often based on physical laws. For example, the sum of maximum 
Figure 8 Information flow percentages in the systemand the assembly-level DSMS

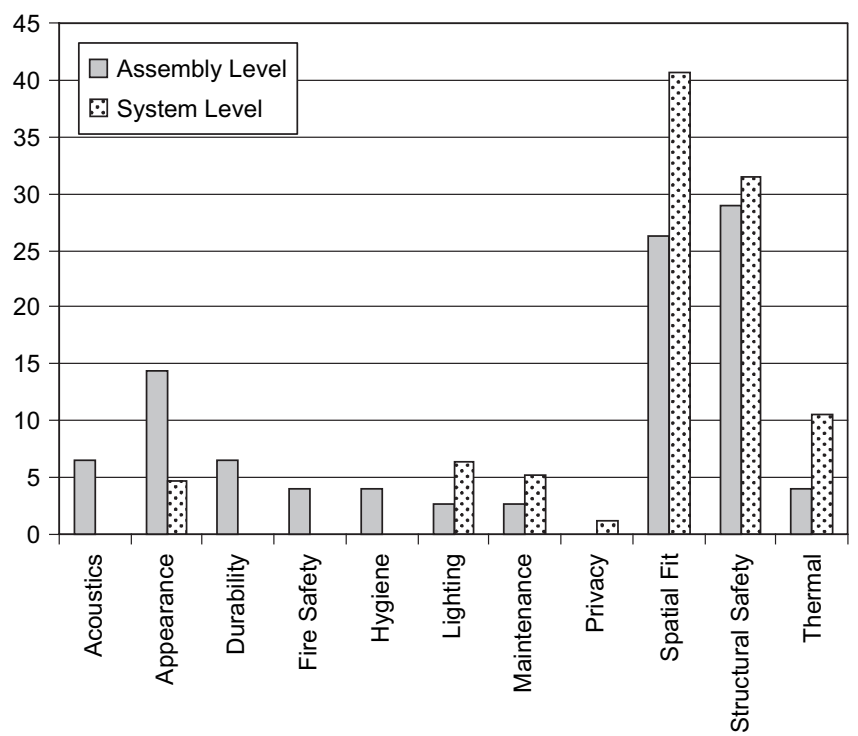

weights of air diffusers and lighting fixtures that can be carried by the suspended ceiling structure is equal to the load test data of the system.

2. Some parameters create constraints for other parameters. In other words, they bring about limitations on the choices for other parameters. For example, in suspended ceiling design, beam depth puts limitations on the minimum plenum depth.

3. Design professionals use preferences to decide on a parameter value when no other parameter dictates a choice. These preferences can be measured with an ordinal scale. Preferences with a higher value are considered as being more important (e.g. lowest cost). This is often the case when decisions are made on finishes. Parameters related to finishes are mostly not dependent on other parameters (although they depend on each other to ensure compatibility in design), but based on client's and/or designer's preferences.

4. When a design problem occurs, for example, when a violation of a constraint indicates that a rework is needed, the designers use fixes to modify the design. Each fix affects specific parameters that are dependent on the changed parameter. Parameter-based DSM is very useful to track the parameters affected by such changes.

In the case study, it was also observed that certain aspects of design are more prone to iterations. First of all, it was observed that early design stage includes more iterative cycles. The problematic situation of early design (also called conceptual design) is well addressed in the literature. 
In building design, most of the important decisions (orientation, circulation, functional layout, etc.) are made in the early stages of design. However, most design software cannot support this stage of design development (Taşlı and Özgüç, 2001).

Decisions made in the early steps of design often have far-reaching and unanticipated impacts at later stages. However, it is often too costly to modify such decisions as the design advances since they affect many parameters and are likely to create 'iterations in iterations.' In order to resolve this dilemma, the assumptions related to early design parameters should be accurate and/or parameter values should be determined with tolerances to compensate for future changes. Making accurate assumptions or deciding on acceptable range of parameter values correctly require to get the right information to the right person at the right time and the DSM method is very useful for this purpose.

Furthermore, it was observed that the most critical parameters, from design management perspective, are those that affect many parameters. These include:

1. System parameters, which affect either all or most of the parameters (e.g. floor area, floor height, etc.).

2. Interface parameters, which specify a relation between two system components engineered by different design professionals (fitting dimensions, forces to be transmitted, etc.).

A major challenge of the proposed parameter-based DSM approach is the large number of parameters involved in building design. The number of parameters needed to fully determine the properties of a product depends on its complexity. Rouibah and Caskey (2003) estimate that an automobile can be described by $10^{5}-10^{6}$ parameters, while an aircraft or ship may have more than $10^{6}$. There is no available estimation of approximately how many parameters a building may involve, but a fairly large number is to be expected. Consequently, to capture and manage all describing parameters in building design may be unrealistic. Therefore, a selection should be made depending on the purpose of the parameter deployment. If the number of considered parameters is based on the critical parameters mentioned above, the number of parameters to be captured reduces considerably.

Finally, the DSM analyses revealed that the technical aspects of designing a building part are usually well understood and relatively easy to manage. Suspended ceiling design at assembly level is an example of 
this type of design which is also called 'standard design' or 'kit-of-theparts' design. However, problems often occur when parts are integrated into a system, and have to interact with other elements in the system. Suspended ceiling design at system level is an example for this phenomenon. This latter type of design is difficult to manage and often not suitable for automation. In most of the cases, human intervention is essential to deal with the conflicts in system-level design. The DSM method is especially useful for modelling complex system designs because of its analytical and concise representation scheme.

\section{Conclusions}

The AEC industry, like many others, is increasingly aware of the need to improve efficiency of processes in a competitive marketplace. However, the industry has experienced difficulties in identifying ways of capturing, understanding, and replicating design processes. Guided by the observations above, this paper has proposed parameter-based DSM as a system analysis and process modelling tool for building design. In a case study, it is shown that parameter-based DSMs provide a structural map of the design processes. They identify iterative cycles, critical parameters, and assumptions that need to be made. They also suggest proper sequence of design decisions and provide insights into the concurrency in the processes. Although the method has a prescriptive value, unlike many other process modelling methods used in the industry, DSM analysis does not dictate a single 'right' process. Instead, it pictures the structure of the dependency relations in the process so that designers may produce several 'what-if' scenarios to determine the effects of change. An illustrative case for the "whatif' scenarios was presented in a paper by Baldwin et al. (1998).

DSM models represent extensive system knowledge. Thus, they are very work intensive and they can be difficult to build initially. In practice, DSM-based approaches may have to overcome barriers such as lack of source documentation, ignorance or lack of system thinking. However, our experience with design professionals suggested that with a short time of learning and application, experts developed an understanding of DSM and responded positively to it. Although it is very knowledge intensive, the DSM method enabled the representation of the processes studied in the case studies in a compact form. If the same processes were modelled with a graphical technique, the models would probably occupy numerous sheets. Thus, their management and integration would be a considerable problem.

The case study also revealed that, in most cases, the design knowledge needed to resolve design issues resides in more than one design 
professional. The database developed in the study showed what information needs to be exchanged as well as dependencies between the decisions. A database as such can serve to accumulate the learning in design firms, providing a complement to the existing inefficient documentation practice. It can serve as a browser for designers to find out what decision they need to make and with whom they need to communicate.

A parameter-based DSM can be effectively used as a tool to control the change propagation. In an on-going design process, when a parameter value is changed, it is very easy to extract the affected parameters using the dependency network. During collaborative design, as different design participants decide on parameter values, capturing the relationship between parameters consequently specifies the relationship between the decision-makers. Who should be informed about a change and the sequence of actions that should be taken can also be easily determined using the tool. Similarly, when the design is finished the model may be used in monitoring changes in the design process to avoid oversight. Terwiesch and Loch (1999) demonstrated such a use of the model in the case of a climate control system in automobile development.

The use of parameter-based DSM in building design may trigger further researches in many directions. For example, this paper utilized only binary parameter-based DSMs. Further research may be done to enhance the existing models by assigning numerical values to the dependencies to qualify the importance and strength of the dependency. A multitude of other attributes that provide more detailed information on the relationships can also be provided. The probability of repetition, the variability of information exchanged, and the impact of an iteration can also be included in the analysis in order to simulate the modelled processes.

Parameter-based DSM facilitates comparison of different design configurations. A DSM can be produced for each design option and different designs may be compared in terms of their complexity and how a change in design affects the overall process structure. In this case, the amount of system elements and information flows would be a good indicator of design complexity. When design configurations are compared, their problematic aspects can be identified and new designs can be modified in the light of the gained insights.

Finally, parameter-based DSMs are truly integrative applications and a combinational use of top-down and bottom-up techniques in process modelling may reveal valuable insights into the process structure. A discussion on how the parameter-based DSM can be used to integrate an 
activity-level AEC process model is presented elsewhere (Pektaş, 2003c). We are currently working to exploit this capability of the method and to develop it as a tool available for using in any building design project.

\section{Acknowledgements}

The authors would like to thank TEPE Construction Company and the design professionals who have contributed to the case study.

\section{References}

Arditi, D and Günaydın, H M (1998) Factors that affect process quality in the life cycle of building projects Journal of Construction Engineering and Management Vol 124 No 3 pp 194-203

Austin, S, Baldwin, A, Li, B and Waskett, P (1999) Analytical design planning technique: a model of the detailed design process Design Studies Vol 20 No 3 pp 279-296

Austin, S, Newton, A, Steele, J and Waskett, P (2002) Modeling and managing project complexity International Journal of Project Management Vol 20 pp 191-198

Baldwin, A N, Austin, S, Hassan, T M and Thorpe, A (1999) Modelling information flow during the conceptual and schematic stages of building design Construction Management and Economics Vol 17 pp 155-167

Baldwin, A N, Austin, S, Hassan, T M and Thorpe, A (1998) Planning building design by simulating information flow Automation in Construction Vol 8 pp 149-163

Black, T A, Fine, C F and Sachs, E M A (1990) Method for systems design using precedence relationships: an application to automotive break systems, Working Paper, MIT School of Management, Cambridge, MA, USA Browning, T R (1998) Modeling and analyzing cost, schedule, and performance in complex system product development, Ph.D. Dissertation, Technology, Management, and Policy Program, Massachusetts Institute of Technology

Browning, T R (2001) Applying the design structure matrix to system decomposition and integration problems: a review and new directions IEEE Transactions on Engineering Management Vol 48 No 3 pp 292-306

Cesiel, D S (1993) A structured approach to calibration development for automotive diagnostic systems, M.Sc. Dissertation, Department of Electrical Engineering, Massachusetts Institute of Technology

Chen, C, Ling, S F and Chen, W (2003) Project scheduling for collaborative product development using DSM International Journal of Project Management Vol 21 pp 291-299

Choo, H J, Hammond, J, Tommelein, I D, Austin, S M and Ballard, G (2004) DePlan: a tool for integrated design management Automation in Construction Vol 13 pp 313-326

Clarkson, P J and Hamilton, J R (2000) "Signposting", a parameter-driven task-based model of the design process Research in Engineering Design Vol 12 pp $18-38$

Cornick, T (1991) Quality management for building design ButterworthHeinemann, London, UK 
Cross, N A (1989) Engineering design methods John Wiley and Sons, Chichester, UK

de la Garza, J and Alcantara, P (1997) Using parameter dependency network to represent design rationale Journal of Computing in Civil Engineering Vol 11 No 2 pp 102-112

Dong, Q (1999) Representing information flow and knowledge management in design using the design structure matrix, M.Sc. Dissertation, Department of Mechanical Engineering, Massachusetts Institute of Technology

English, K, Bloebaum, C L and Miller, E (2001) Development of multiple cycle coupling suspension in the optimization of complex systems Structural and Multidisciplinary Optimization Vol 22 No 4 pp 268-283

Eppinger, S D, Whitney, D E, Smith, R P and Gebala, D A (1994) A modelbased method for organizing tasks in product development Research in Engineering Design Vol 6 pp 1-13

Formoso, C T , Tzotzopoulos, P, Jobim, M S S and Liedtke, R (1998) Developing a protocol for managing the design process in the building industry, International Group for Lean Construction, Sixth Annual Conference, Retrieved May 2002 from: http://www.ce.berkeley.edu/ tommelein/ IGLC-6/FormosoTzotzopoulosJobimLeidtke.pdf

Hirschi, N W and Frey, D D (2002) Cognition and complexity: an experiment on the effect of coupling in parameter design Research in Engineering Design Vol 13 pp 123-131

Hong, N K and Hong, S (2001) Application of entity-based approach for unified representation of design alternatives for structural design Advances in Engineering Software Vol 32 pp 599-610

Hornby A S, Kavanagh K and Ashby M (eds) (1995) Oxford advanced learner's english dictionary $5^{\text {th }}$ edn, Oxford University Press, UK

Hubka, V (1982) Principles of engineering design Butterworth Scientific Press, Guildford, Surrey, UK

Huovila, P and Seren, K J (1998) Customer-oriented design methods for construction projects Journal of Engineering Design Vol 9 No 3 pp 225-238 Karhu, V (2000) Proposed new method for construction process modelling International Journal of Computer Integrated Design and Construction Vol 2 No 3 pp 166-182

Krishnan, W (1993) Design process improvement: sequencing and overlapping activities in product development, Ph.D. Dissertation, Department of Mechanical Engineering, Massachusetts Institute of Technology

Malmström, J, Pikosz, P and Malmqvist, J (1999) Complementary roles of IDEF0 and DSM for the modelling of information management processes Concurrent Engineering - Research and Applications Vol 7 No 2 pp 95-103

Mascoli, G J (1999) A systems engineering approach to aero engine development in a highly distributed engineering and manufacturing environment, MIT SDM Thesis, Massachusetts Institute of Technology

MIT DSM Research Group (2005) MIT DSM Web Site http:// www.dsmweb.org/

Pahl, G and Beitz, W (1984) Engineering design The Design Council, London, UK

Pektaş, Ş T (2003a) A framework for building design process modeling with parameter-based design structure matrices in $\mathbf{C} \mathbf{J}$ Anumba (ed) 
Innovative developments in architecture, engineering and construction, Millpress, Rotterdam, The Netherlands pp 63-72

Pektaş, S T (2003b) Representing information flow in building design process using the parameter-based design structure matrix, Ph.D. Dissertation, Bilkent University, Ankara

Pektaş, S T (2003c) Process integration in building design using the parameter-based design structure matrix in B Tunçer, S S Ozsariyildiz and S S Sariyildiz (eds) E-Activities in building design and construction, Europia Productions, Paris, France pp 63-72

Phillips, R (2001) The architect's plan of work RIBA Publications, London, UK

Pugh, S (1986) Design activity models: worldwide emergence and convergence Design Studies Vol 7 No 3 pp 167-173

Pultar, M (1990) Progress based construction scheduling Journal of Construction Engineering and Management Vol 116 No 4 pp 670-688

Rezgui, Y, Zarli, A, Bourdeau, M and Cooper, G (2002) Inter-enterprise information management in dynamic virtual environments: the OSMOS approach, Proceedings of the International Council for Research and Innovation in Building and Construction CIB W78 Conference, Retrieved February 15, 2003, from http://cic.cstb.fr/ilc/publicat/rezgui_cibw78.pdf

Rogers, J L and Salas, A O (1999) Toward a more flexible web-based framework for multidisciplinary design Advances in Engineering Software Vol 30 pp 439-444

Rotheroe, K (2002) A vision for parametric design, Architecture Week, Retrieved December 2002, from http://www.architectureweek.com/2002/0710/ tools_1-1.html

Rouibah, K and Caskey, K R (2003) Change management in concurrent engineering from a parameter perspective Computers in Industry Vol $50 \mathrm{pp} 15-34$ Rounce, G (1998) Quality, waste and cost considerations in architectural building design management International Journal of Project Management Vol 16 No 2 pp 123-127

Rundell, R L (2002) Parametrics in building design, CAD Server: Online Resource for the CAD Community, Retrieved December 2002, from http:// www.cadserver.co.uk/common/viewer/archive/2002/Apr/9/feature.htm Sanvido, V E and Norton, K J (1994) Integrated design process model Journal of Management in Engineering Vol 5 pp 55-62

Smith, R P and Eppinger, S D (1999) A predictive model of sequential iteration in engineering design Management Science Vol 43 pp 1104-1120

Steward, D V (1981) The design structure system: a method for managing the design of complex systems IEEE Transactions on Engineering Management Vol 28 pp 71-74

Tang, D, Zheng, L, Li, Z, Li, D and Zhang, S (2000) Re-engineering of the design process for concurrent engineering Computers and Industrial Engineering Vol 38 pp 479-491

Taşlı, Ş and Özgüç, B (2001) Dynamic simulation in virtual environments as an evaluation tool for architectural design Architectural Science Review Vol 44 No 2 pp 139-144

Terwiesch, C and Loch, C H (1999) Managing the process of engineering change orders: the case of the climate control system in automobile development Journal of Product Innovation Management Vol 16 pp 160-172 
Tolman, F P (1999) Product modelling standards for the building and construction industry: past, present and future Automation in Construction Vol 8 pp $227-235$

Wakefield, R R and Damrianant, J (1999) Petri net modelling - a simulation tool for use in construction process re-engineering International Journal of IT in Architecture, Engineering, and Construction Vol 1 No 2 pp 20-34

Wu, S, Fleming, A, Aouad, G and Cooper, R (1998) The development of the process protocol mapping methodology and the tool, Proceedings of the European Product Data Technology Conference, Building Research Establishment, Watford, UK, Retrieved April 2002, from http://pp2.dct.salford. ac.uk/pdf/pdt98.pdf 